\title{
Right Aortic Arch Associated with Left Internal Carotid Artery Agenesis
}

\author{
Yu lida, ${ }^{1,2}$ Hiroshi Nagamine, ${ }^{3}$ and Motohiro Nomura ${ }^{1,4}$
}

\begin{abstract}
We report the rare case of a right aortic arch associated with agenesis of the left internal carotid artery. A 75-yearold woman with a medical history of tetralogy of Fallot presented with dizziness. Magnetic resonance angiography revealed agenesis of the left internal carotid artery in addition to a previously diagnosed right aortic arch. The left common carotid artery was present, but it was thin. Computed tomography showed the absence of the left carotid canal. The left anterior cerebral artery was fed via the anterior communicating artery. The left middle cerebral artery was fed via a thickened posterior communicating artery originating from the left posterior cerebral artery. Although a right aortic arch and agenesis of the internal carotid artery are both very rare, association of the two conditions may occur. Both anomalies depend on the abnormal regression of the dorsal aorta during embryonic development. In such a situation, the presence of other anomalies in the cardiac or central nervous system should be taken into consideration.
\end{abstract}

Keywords: right aortic arch, agenesis, internal carotid artery, congenital anomaly

\section{Introduction}

A right aortic arch is a rare congenital anomaly. ${ }^{1)}$ A right aortic arch has been reported to be associated with several cardiovascular anomalies. ${ }^{2)}$ On the other hand, agenesis of the internal carotid artery (ICA) is also rare. ${ }^{3)}$ Even in such a situation, the collateral circulation is commonly sufficient to maintain the cerebral function with few or no neurological symptoms. ${ }^{3)}$ In this report, we describe a patient with the rare association of a right aortic arch and agenesis of the unilateral ICA, and discuss the radiological findings, etiology, and clinical course.

\section{Case Presentation}

A 75-year-old woman with a past history of a right aortic arch and tetralogy of Fallot (TOF) experienced dizziness.

\footnotetext{
${ }^{1}$ Department of Neurosurgery, Yokohama Sakae Kyosai Hospital, Yokohama, Kanagawa, Japan

${ }^{2}$ Department of Neurosurgery, Yokohama Rosai Hospital, Yokohama, Kanagawa, Japan

${ }^{3}$ Department of Cardiovascular Surgery, Yokohama Sakae Kyosai Hospital, Yokohama, Kanagawa, Japan

${ }^{4}$ Department of Neurosurgery, Kanto Rosai Hospital, Kawasaki, Kanagawa, Japan
}

Received: September 19, 2016; Accepted: February 9, 2017 Online June 7, 2017
She reported that she had undergone surgery for TOF at the age of 48 years old. However, detailed information was not available. Magnetic resonance angiography (MRA) and computed tomography (CT) showed a right aortic arch (Figs. 1A and 1B) and the absence of the left ICA (Fig. 1C). magnetic resonance image (MRI) showed no brain abnormality that could cause dizziness. The left anterior cerebral artery (ACA) was fed via the anterior communicating artery. The left middle cerebral artery (MCA) was fed via a posterior communicating artery (PComA) (Fig. 1D). According to its running course, ICA distal to the PComA seemed to exist. On MRA, origin and running course of the left ophthalmic artery could not be observed. Arterial spin labeling (ASL) of MRI revealed no decrease of cerebral blood flow (CBF) in the left cerebrum (Fig. 1E). CT demonstrated the absence of the left carotid canal, consistent with congenital agenesis of the ICA (Fig. 1F). Her symptom was not diagnosed based on the absence of ICA, and it improved spontaneously.

\section{Discussion}

Agenesis of the ICA is a very rare congenital anomaly, occurring in less than $0.01 \%$ of the population. ${ }^{3)}$ An association with some anomalies in the central nervous system, such as cerebral hemiatrophy, arachnoid cyst, neurofibromatosis, and Klippel-Feil syndrome, has been reported. ${ }^{4)}$ As for the association with cardiac anomalies, Fitzgerald et al. ${ }^{5)}$ reported that $78 \%$ of patients with ICA agenesis had a congenital aortic or cardiac anomaly including TOF, coarctation, a hypoplastic left heart, and muscular ventricular septal defect. TOF is a congenital heart disease and has been classically characterised by the combination of ventricular septal defect, pulmonary stenosis, an overriding aorta, and a right ventricular hypertrophy. Our patient had TOF and underwent surgery when she was 48 years old. In addition, our patient had a right aortic arch. Although a right aortic arch is a rare congenital anomaly with an incidence of $0.05-0.1 \%,{ }^{1)}$ it is found in $25 \%$ of patients with $\mathrm{TOF}^{6}{ }^{6}$ On the other hand, the association of a right aortic arch and agenesis of the ICA is very rare. To our knowledge, only 7 cases have been reported (Table 1). ${ }^{1,6-11)}$

The development of the aorta takes place during the third week of gestation. ${ }^{12)}$ Each primitive aorta consists of ventral and dorsal aortae, and 6 paired aortic arches (branchial arch arteries) developing between the ventral and dorsal aortae (Fig. 2A). Normally, the ICA is derived from portions of the third aortic arch and dorsal aorta, when the embryo has reached the $3-\mathrm{mm}$ stage. The root portion of the ICA is 

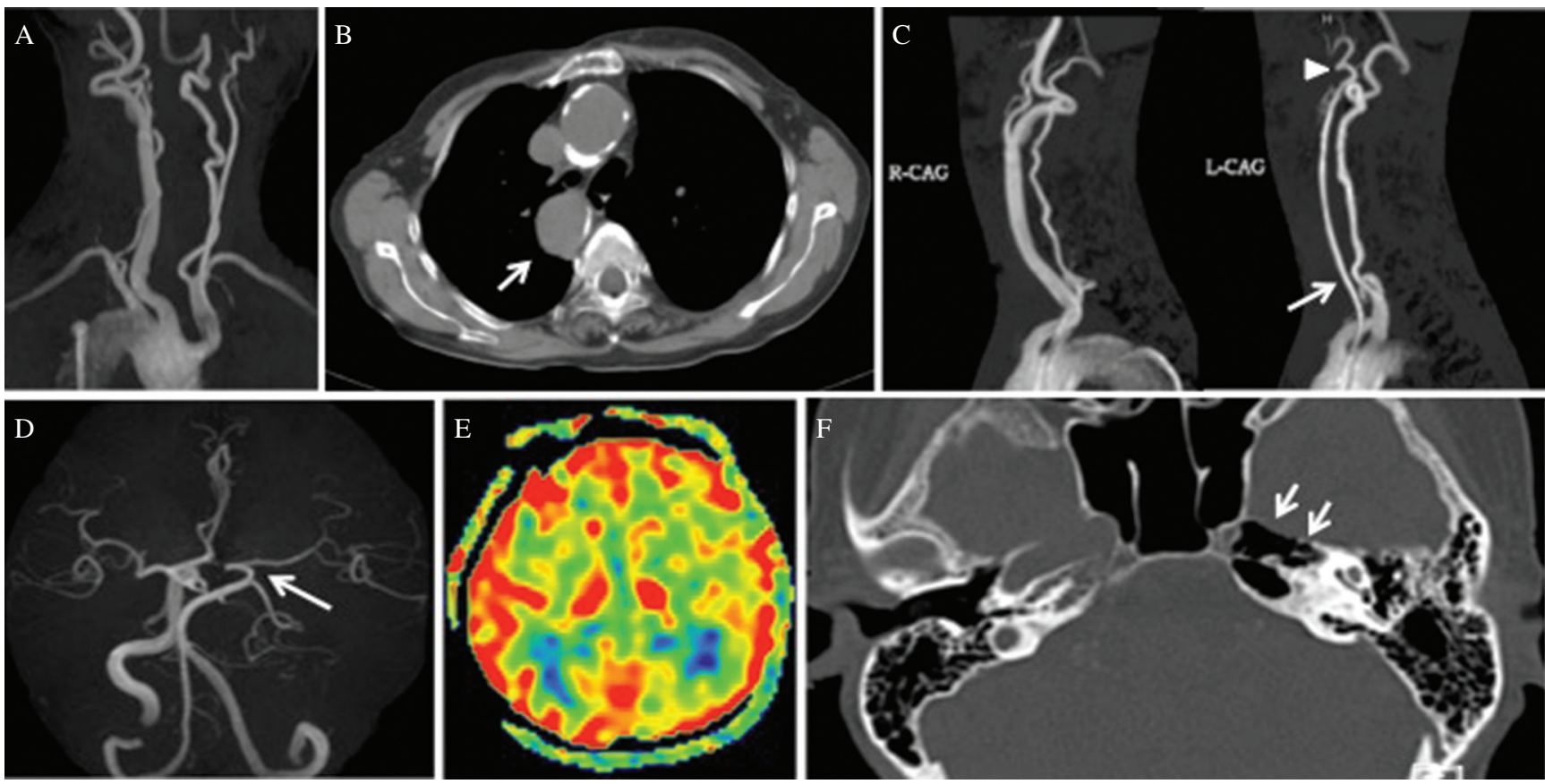

Fig. 1 Radiological findings. (A) Magnetic resonance angiography (MRA) showing the right aortic arch, (B) Computed tomography (CT) showing the descending aorta on the right side (arrow), (C) MRA showing the absence of the left ICA from its origin at the neck (arrowhead). The diameter of the left common carotid artery (arrow) is small compared with the right, (D) MRA demonstrating that the left anterior cerebral artery is fed via the anterior communicating artery. The left middle cerebral artery is fed via the thickened posterior communicating artery (arrow) from the posterior cerebral artery, (E) Arterial spin labeling images showing no decrease of cerebral blood flow in the left cerebrum, (F) CT demonstrating the absence of the left carotid canal (arrows), consistent with congenital agenesis of the internal carotid artery.

Table 1 Summary of cases with right aortic arch and internal carotid artery agenesis

\begin{tabular}{|c|c|c|c|c|c|c|c|c|c|c|}
\hline No & Author & Year & $\begin{array}{l}\text { Age } \\
\text { (y.o.) }\end{array}$ & Sex & $\begin{array}{l}\text { Absent side } \\
\text { of the ICA }\end{array}$ & Clinical feature & $\begin{array}{l}\text { Aberrant } \\
\text { subclavian } \\
\text { artery }\end{array}$ & $\begin{array}{l}\text { Intracranial } \\
\text { aneurysm }\end{array}$ & $\begin{array}{c}\text { Carotid } \\
\text { canal of CT }\end{array}$ & Other anomaly \\
\hline 1 & Suzuki et al.9) & 1984 & 27 & $\mathrm{~F}$ & Bilateral & $\begin{array}{l}\text { Syncope, right } \\
\text { hemiconvulsion }\end{array}$ & + & - & Absence & - \\
\hline 2 & Alexander et al. ${ }^{7)}$ & 1984 & 63 & $\mathrm{~F}$ & Left & Infarction & - & - & Absence & $\begin{array}{l}\text { Hypoplasia of the right } \\
\text { temporal lobe }\end{array}$ \\
\hline 3 & Rumboldt et al. ${ }^{10)}$ & 2003 & 11 & M & Bilateral & $\begin{array}{l}\text { Chronic } \\
\text { headaches }\end{array}$ & - & - & Absence & $\begin{array}{l}\text { Patent ductus } \\
\text { arteriosus, pulmonary } \\
\text { stenosis }\end{array}$ \\
\hline 4 & Dainese et al. ${ }^{1)}$ & 2009 & 31 & $\mathrm{~F}$ & Left & $\begin{array}{l}\text { Left arm } \\
\text { claudication, } \\
\text { hyposthenia }\end{array}$ & + & $?$ & $?$ & $\begin{array}{l}\text { Aneurysm of the } \\
\text { Kommerell } \\
\text { diverticulum }\end{array}$ \\
\hline 5 & Paredes et al. ${ }^{6}$ & 2015 & 6 weeks & M & Right & $\begin{array}{l}\text { Heart murmur, } \\
\text { cyanosis }\end{array}$ & - & $?$ & $?$ & $\begin{array}{l}\text { TOF, left pulmonary } \\
\text { artery arising from the } \\
\text { ascending aorta }\end{array}$ \\
\hline 6 & Yamasaki et al. ${ }^{11)}$ & 2015 & 50 & M & Left & $\begin{array}{l}\text { Subarachnoid } \\
\text { hemorrhage }\end{array}$ & - & + & Absence & $\begin{array}{l}\text { Isolation of the left } \\
\text { innominate artery, } \\
\text { dysplasia of the } \\
\text { posterior circulation } \\
\text { on the left side }\end{array}$ \\
\hline 7 & Okawa et al. ${ }^{8)}$ & 2015 & 26 & $\mathrm{~F}$ & Right & Tinnitus & + & - & Absence & - \\
\hline 8 & Present case & 2016 & 75 & F & Left & Dizziness & - & - & Absence & TOF \\
\hline
\end{tabular}

F: female; M: male; TOF: tetralogy of Fallot. 

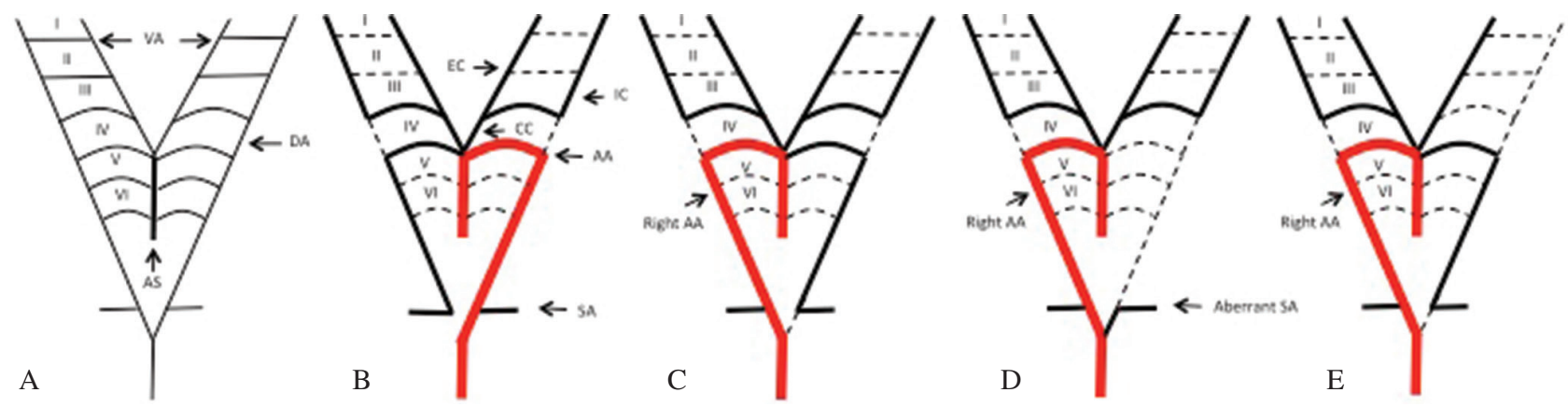

Fig. 2 Schematic drawing of the development of an aortic arch and its branches (A) Normal anatomy of primitive aorta, (B) Normal development of thoracic and cervical arteries, (C) Schematic drawing indicating the development of the right aortic arch with mirror-image branching, (D) Schematic drawing indicating the development of the right aortic arch with aberrant subclavian artery, (E) Schematic drawing indicating the development of the right aortic arch and agenesis of the left ICA (present case). I-VI 1st - 6th aortic arch, AA aortic arch, AS aortic sac, CC common carotid artery, DA dorsal aorta, EC external carotid artery, IC internal carotid artery, SA aubclavian artery, VA ventral aorta.

formed from the third aortic arch, and its distal portion arises from the distal portion of the dorsal aorta (Fig. 2B). ${ }^{4,12}$ Therefore, agenesis of the ICA is based on the atresia or involution of the third aortic arch and the distal portion of the dorsal aorta in the 20-24-mm stage.

As for the right aortic arch, it depends on the abnormal regression of the left fourth arch and left dorsal aorta. ${ }^{13)}$ The left fourth arch and dorsal aorta form the normal left aortic arch. Regression of the right dorsal aortic root (between the right subclavian artery and descending aorta) leaves the normal left aortic arch (Fig. 2B). However, in cases with right aortic arch, the right dorsal aortic root persists and a right aortic arch is formed by regression of the left fourth arch and left dorsal aorta during embryonic development (Fig. 2C). Knight \& Edward ${ }^{14)}$ classified the right aortic arch into two groups as follows: (I) that with a retroesophoageal aortic segment and (II) that without a retroesophoageal aortic segment. The latter cases could be subdivided according to the nature of the origin of the branches of the arch as follows: (II-1) mirror-image branching, (II-2) aberrant left subclavian artery, and (3) isolation of left subclavian artery. Congenital heart disease, of which the TOF was most common, was observed in each of the cases of right aortic arch without a retroesophoageal aortic segment.

The mirror-image branching pattern develops by regression of the distal part of the left dorsal aorta extending from the origin of the right seventh intersegmental artery (future right subclavian artery) to the junction point of both dorsal aortae and simultaneous persistence of the corresponding section of right dorsal aorta (Fig. 2C). The aberrant left subclavian artery is attributed to involution of the proximal part of the left dorsal aorta starting from the junction point of the left third arch artery to the origin of the left seventh intersegmental artery (Fig. 2D). ${ }^{15)}$ The aberrant left subclavian artery arising from a right aortic arch is extremely rare (0.05-0.1\% of the population). ${ }^{16)}$

In our patient, the right aortic arch was the mirror-image branching type (II-1) with TOF and she also had agenesis of the ICA. (Fig. 2E)

Thus, both a right aortic arch and agenesis of the ICA are associated with the abnormal regression of the dorsal aorta.
Therefore, it might be reasonable to assume that a patient diagnosed with a right aortic arch or agenesis of the left ICA also has the other.

Regarding clinical characteristics, in a case of agenesis of the ICA, the main collateral pathways include the circle of Willis and transcranial collaterals via the external carotid artery. Although many of the patients are asymptomatic, recognition of this vascular anomaly is important because of the potential complications of aneurysm formation and rupture later in life. ${ }^{6)}$ The reported incidence of aneurysms in association with agenesis of the ICA is 24 to $34 \%{ }^{3)}$ Increased flow through collateral vessels and altered flow dynamics are responsible for this increased prevalence. The anterior communicating artery is the most frequent site of aneurysm formation in such cases. ${ }^{3)}$

In addition, Imaizumi et al ${ }^{17)}$ reported a case with TOF and agenesis of the ICA who presented serious intracerebral hematomas. They speculated that brain hypoxia caused by TOF and agenesis of the ICA played an important role as a pathogenesis of the intracerebral hematomas. Hasan et al. ${ }^{18)}$ reported a case of agenesis of the left ICA and an aortic arch anomaly that presented with ipsilateral congenital Horner's syndrome. Agenesis of the ICA may rarely present with congenital Horner's syndrome and also be associated with aortic arch anomaly. In our patient, symptom was only dizziness. Dizziness is not a specific symptom for ICA agenesis. And an aneurysm was not detected in our case.

As for radiological findings of MRI, ICA was found to be missing. It is sometimes seen in cases of atherosclerotic ICA occlusion. However, in our case, collateral flow was developed. And the findings were different from those of atherosclerosis. Therefore, CT was additionally performed, and carotid canal defect was detected. In cases of ICA deficiency, congenital defect of ICA should be taken into consideration.

\section{Conclusion}

A right aortic arch and agenesis of the ICA are both rare vascular anomalies. The presence of both anomalies is extremely rare. Etiology of the both anomalies might be associated with the abnormal regression of the dorsal aorta. 
Although most cases of ICA agenesis are asymptomatic, the potential complication of cerebral aneurysm should be considered. If patients with agenesis of the ICA have various congenital aortic or cardiac anomalies, brain hypoxia caused by the ICA agenesis and cardiac anomalies might play an important role as a pathogenesis of the intracerebral hematomas.

\section{Conflicts of Interest Disclosure}

The authors have no personal financial or institutional interest in any of the drugs, materials or devices in the article.

\section{References}

1) Dainese L, Spirito R, Barili F, Fusari M, Trabattoni P, Sommaruga $S$, Andreini D, Cappai A, Biglioli P: Right aortic arch related to Kommerell diverticulum and internal carotid artery agenesis. Circ Cardiovasc Imaging 2: e6-e7, 2009

2) Hastreiter AR, D'Cruz IA, Cantez T, Namin EP, Licata R: Right-sided aorta. I. Occurrence of right aortic arch in various types of congenital heart disease. II. Right aortic arch, right descending aorta, and associated anomalies. Br Heart J 28: 722-739, 1966

3) Given CA, Huang-Hellinger F, Baker MD, Chepuri NB, Morris PP: Congenital absence of the internal carotid artery: case reports and review of the collateral circulation. AJNR Am J Neuroradiol 22: 1953-1959, 2001

4) Lee JH, Oh CW, Lee SH, Han DH: Aplasia of the internal carotid artery. Acta Neurochir (Wien) 145: 117-125; discussion 125, 2003

5) Fitzgerald RT, Zuccoli G: Agenesis of the internal carotid artery: associated malformations including a high rate of aortic and cardiac malformations. Pediatr Radiol 42: 1333-1338, 2012

6) Paredes AM, Caspi J, Lilje C: Tetralogy of Fallot and anomalous origin of the left pulmonary artery from the ascending aorta associated with absent right internal carotid artery. World J Pediatr Congenit Heart Surg 6: 324-327, 2015

7) Alexander MW, Chui MC, Gray T: Transellar intercavernous carotid anastomosis with agenesis of internal carotid artery and right-sided descending aorta: case report. J Can Assoc Radiol 35: 92-95, 1984

8) Okawa M, Higashi T, Komiyama M, Fukuda K, Abe H, Inoue T: Left internal carotid artery agenesis with trans-sellar collateral and a right aortic arch: Case report. Interv Neuroradiol 21: 759-764, 2015

9) Suzuki N, Tanaka N, Hirata K, Yamashita Y, Shiozawa T: [Dysgenesis of the bilateral internal carotid arteries. Case report]. Neurol Med Chir (Tokyo) 24: 881-885, 1984

10) Rumbolt $Z$, Castillo M, Solander S: Bilateral congenital absence of the internal carotid artery. Eur Radiol 13: L130-L132, 2003

11) Yamasaki K, Yokogami K, Ohta H, Yamashita S, Kawasoe T, Takeshima H: Agenesis of the left internal carotid artery in the right aortic arch with isolation of the left innominate artery associated with ruptured cerebral aneurysm: case report. NMC Case Rep J 2: 46-48, 2015

12) Kau T, Sinzig M, Gasser J, Lesnik G, Rabitsch E, Celedin S, Eicher W, Illiasch H, Hausegger KA: Aortic development and anomalies. Semin Intervent Radiol 24: 141-152, 2007

13) Barry A: The aortic arch derivatives in human adult. Anat Rec 111: 221-238, 1951

14) Knight L, Edwards JE: Right aortic arch. Types and associated cardiac anomalies. Circulation 50: 1047-1051, 1974

15) Craatz S, Künzel E, Spanel-Borowski K: Right-sided aortic arch and tetralogy of Fallot in humans-a morphological study of 10 cases. Cardiovasc Pathol 12: 226-232, 2003

16) Ota T, Okada K, Takanashi S, Yamamoto $S$, Okita Y: Surgical treatment for Kommerell's diverticulum. J Thorac Cardiovasc Surg 131: 574-578, 2006

17) Imaizumi S, Sakurai $Y$, Suzuki H, Onuma T, Kameyama M, Oto T: Intracerebral haematomas with agenesis of the internal carotid artery and tetralogy of Fallot. Acta Neurochir (Wien) 143: 625-629, 2001

18) Dinç H, Alioglu Z, Erdöl H, Ahmetoglu A: Agenesis of the internal carotid artery associated with aortic arch anomaly in a patient with congenital Horner's syndrome. AJNR Am J Neuroradiol 23: 929-931, 2002

Corresponding author:

Yu Iida, Department of Neurosurgery, Yokohama Rosai Hospital, 3211 Kozukue-cho, Kohoku-ku, Yokohama, Kanagawa 222-0036, Japan.

$\triangle$ yuiida1204@gmail.com 